\title{
A Novel Modified Tissue-Type Plasminogen Activator (t-PA), E6010, Gradually Increases Coronary Blood Flow after Thrombolysis Compared with Native t-PA, Urokinase and Balloon Catheter Occlusion-Reperfusion
}

\author{
Mamoru Saito ${ }^{1}$, Suguru Suzuki ${ }^{1}$, Yoshiki Yui ${ }^{2}$ and Chuichi Kawai ${ }^{2}$ \\ ${ }^{1}$ Tsukuba Research Laboratories, Eisai Co., Ltd., 5-1-3 Tokodai, Tsukuba, Ibaraki 300-26, Japan \\ ${ }^{2}$ Third Division, Department of Internal Medicine, Faculty of Medicine, Kyoto University, Kyoto 606-01, Japan \\ Received January 5, 1994 Accepted June 1, 1994
}

\begin{abstract}
In a canine copper coil-induced coronary thrombosis model, the differences in frequency of reperfusion arrhythmias (premature ventricular complexes: PVC) and mortality rate after thrombolysis by intravenous bolus injection of a novel modified tissue-type plasminogen activator (t-PA), E6010, and by continuous intravenous infusion of native t-PA or urokinase were evaluated. Rapid coronary occlusion and reperfusion were produced with a balloon catheter in another group of dogs, and the findings were compared with those in the thrombolysis groups. Reperfusion occurred gradually after the administration of E6010, but was significantly more rapid after administration of native t-PA and urokinase $(\mathrm{P}<0.05)$. PVC were observed more frequently in native t-PA, urokinase and balloon occlusion-reperfusion groups than in the E6010 group. The mortality rate due to ventricular fibrillation was $0.0 \%$ in the E6010 group, $50.0 \%$ in the native t-PA and balloon occlusion-reperfusion groups, and $33.3 \%$ in the urokinase group. These results suggest that the more gradual reperfusion of the coronary artery at an earlier period after drug administration led to the lower frequency of reperfusion arrhythmias and low mortality rate in the E6010 group than in the native t-PA, urokinase and balloon occlusion-reperfusion groups.
\end{abstract}

Keywords: Tissue-type plasminogen activator (modified) (E6010), Coronary thrombolysis, Reperfusion flow, Reperfusion arrhythmia, Mortality

The myocardium rapidly loses its contractile function with a sudden reduction or interruption of the coronary blood flow, but cardiac function recovers with little cell injury if the blood flow is re-established within a short period (1). Analysis of large clinical trials suggests that patency is achieved more rapidly and that there is a greater increase in survival rate of the obstructed coronary artery after the onset of acute myocardial infarction (2-4). Therefore, primary treatment for myocardial infarction involves minimizing the extent of myocardial damage. Furthermore, analysis of large clinical trials in which native tissue-type plasminogen activator (t-PA) was administered early during the course of acute myocardial infarction have shown reduced short- and long-term mortality rates, limited infarct size and improved left ventricular function $(3-5)$.

The clearance of native t-PA through the liver is rapid, resulting in a short plasma half-life $\left(\mathrm{t}_{1 / 2} \alpha: 3.6 \pm 0.23 \mathrm{~min}\right.$, $\mathrm{t}_{1 / 2} \beta: 36 \pm 2.3 \mathrm{~min}$ in dogs) $(6-9)$. Continuous infusion of the drug is thus required to maintain therapeutic blood levels for the treatment of acute myocardial infarction. Recently, we developed a novel modified t-PA, E6010, which was constructed by modifying only a single amino acid in the epidermal growth factor domain $\left(\mathrm{Cys}^{84} \rightarrow\right.$ $\left.\mathrm{Ser}^{84}\right)$. This agent has a long plasma half-life $\left(\mathrm{t}_{1 / 2} \alpha\right.$ : $4.8 \pm 0.95 \mathrm{~min}, \mathrm{t}_{1 / 2} \hat{\beta}: 51 \pm 5.4 \mathrm{~min}$ in dogs), thus allowing intravenous bolus injection (6-9). Experimental $(6-10)$ and clinical (11) studies suggest that E6010 induces a rapid and high rate of reperfusion in coronary thrombosis.

However, because reperfusion arrhythmias can occur on restoration of the coronary blood flow, and because these may advance to more serious arrhythmias such as ventricular fibrillation $(1,12)$, it is currently recommended that thrombolytic therapy is performed only in institutions that have facilities for ECG monitoring and the appropriate management of severe arrhythmias. Therefore, reperfusion arrhythmias caused by thrombolytic therapy may become an important problem in the treatment of myocardial infarction. 
In a previous study, we showed that the frequency of reperfusion arrhythmias and post-perfusion mortality rate were reduced with $\mathrm{E} 6010$ compared with native t-PA and urokinase $(13,14)$. Therefore, the present study was carried out to determine how the restored blood flow can best be maintained in reperfusion arrhythmias (premature ventricular complexes: PVC). We measured the reperfusion blood flow and PVC in dogs with copper coil-induced coronary thrombosis and evaluated the relationship between coronary blood flow during reperfusion, frequency of PVC and mortality rate after thrombolytic therapy. The findings in these groups were also compared with those in a group where abrupt coronary occlusion and reperfusion were created with a balloon catheter.

\section{MATERIALS AND METHODS}

All experiments were conducted according to the Guidelines for the Care and Use of Laboratory Animals published by the US National Institutes of Health (NIH Publication No. 85-23, revised 1985).

\section{Animal model}

Twenty-four adult mongrel dogs (both sexes, $13-21 \mathrm{~kg}$ body weight) were anesthetized with $50 \mathrm{mg} / \mathrm{kg}$ of ketamine hydrochloride (Sankyo Co., Ltd., Tokyo), intramuscularly, followed by $10 \mathrm{mg} / \mathrm{kg}$ of thiopental sodium (Tanabe Seiyaku Co., Ltd., Osaka), intravenously. They were later assigned randomly to four groups $(n=6)$, as described below. After endotracheal intubation, respiration was controlled with an artificial respirator (ARF850E and EM-2; Acoma Co., Ltd., Tokyo), and anesthesia was maintained with a gas mixture of $\mathrm{O}_{2}$, nitrous oxide $\left(\mathrm{NO}_{2}\right)$ and $0.8-1.5 \%$ enflurane (Dainabot Co., Ltd., Osaka). All animals were ventilated with positive pressure at a stroke volume of $20 \mathrm{ml} / \mathrm{kg}$ and a frequency of 12 inflations $/ \mathrm{min} . \mathrm{O}_{2}$ and $\mathrm{NO}_{2}$ were mixed at a ratio of $1: 2$. Body temperature was maintained at $37-38^{\circ} \mathrm{C}$ with a heating sheet.

Precalibrated catheter tip type transducers (MPC-500; Millar Instruments, Houston, TX, USA) were inserted into the right and left femoral arteries to allow measurement of arterial pressure and left ventricular pressure (LVP). Polyethylene catheters (7-French; Atom Co., Ltd., Tokyo) were used for intravenous injection of drugs.

Thoracotomy was performed in the fifth left intercostal space, and the heart was suspended in a pericardial cradle. The left anterior descending coronary artery (LAD) was dissected free distal to the first major diagonal branch. A precalibrated electromagnetic flow probe (FN020TA; Nihon Kohden, Tokyo) was placed on the LAD for the measurement of coronary blood flow. The probe was carefully matched to the diameter of the artery and was chosen so that it fitted snugly on the coronary artery. ECG was recorded by limb leads I-III. Heart rate was measured with a tachometer (AT-601G, Nihon Kohden), using the left ventricular pressure waveform as the trigger. ECG (lead II), heart rate, phasic blood pressure, mean blood pressure, coronary blood flow, LVP and its first derivative $\mathrm{LVdP} / \mathrm{dt}$ were continuously recorded with a polygraph (RM-6000, Nihon Kohden) during the experiment.

An intracoronary thrombus was induced with the technique initially described by Kordenat et al. (15). Briefly, a copper coil was fashioned by winding 0.29 -mm diameter copper wire (No. 20; Kyowa Densen, Tokyo) around a 19-gauge needle, and then this coil was trimmed to a length of $4-5 \mathrm{~mm}$; this resulted in a coil with an outer diameter of $1.80 \mathrm{~mm}$ and an inner diameter of $1.22 \mathrm{~mm}$. The coil was placed on a guide wire and was inserted into the LAD by using a Sones catheter (8-French; C.R. Bard Inc., Billerica, MA, USA) advanced over the guide wire. The objective was to produce spontaneous thrombosis at the site of the coil. The guide wire and catheter were then withdrawn, and an angiography catheter was reinserted into the ascending aorta. Left coronary angiography was performed 10 min later to confirm thrombosis at the coil and, if occlusion was not achieved at that time, angiography was performed again, $15-20 \mathrm{~min}$ after insertion of the coil.

In the balloon occlusion-reperfusion group, a 3-French balloon catheter (CV-1040; Baxter Healthcare Co., Irvine, CA, USA) was inserted into the left anterior descending coronary artery through the left carotid artery under fluoroscopic guidance. After coronary angiography, the balloon was inflated to institute coronary occlusion at a site immediately distal to the first diagonal branch.

\section{Experimental protocols}

Figure 1 shows the protocol used in the present study. All dogs underwent the LAD occlusion for $1 \mathrm{hr}$ with either the copper coil-induced thrombus or the balloon.

In the copper coil-induced thrombosis model, the animals were randomly assigned to E6010-, native t-PAor urokinase-treated groups. Coronary angiography was again performed to confirm occlusion of the vessel; heparin (300 units $/ \mathrm{kg}$ ) was administered intravenously; and then $\mathrm{E} 6010$, native t-PA or urokinase was administered 1 min later. The predetermined dose of E6010, dissolved in the vehicle $(3 \%$ arginine-aspartic acid salt and $5 \%$ mannitol, $\mathrm{pH} 5.0$ to a volume of $5 \mathrm{ml}$, was administered as a bolus. For native t-PA and urokinase, $10 \%$ of the dose was similarly dissolved in a volume of $5 \mathrm{ml}$ and administered as a bolus, while the remaining $\mathbf{9 0 \%}$ was diluted with $5 \%$ glucose solution to $180 \mathrm{ml}$ and administered 


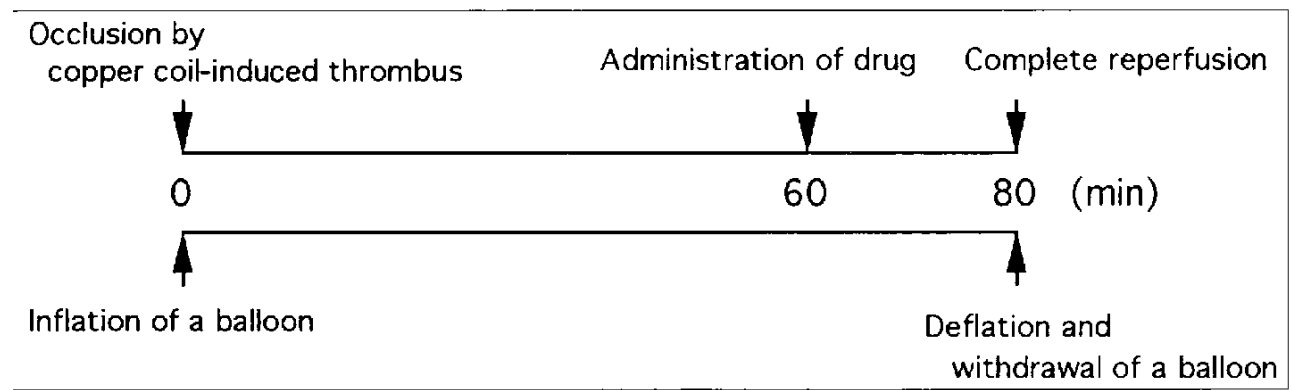

Fig. 1. Diagram of protocol used in the present study for the drug administration groups or balloon occlusion-reperfusion group. The period of occlusion, the timing of drug administration, the time of complete reperfusion and balloon deflation are indicated.

over a 60 -min period, by using an infusion pump. The used doses were $0.2 \mathrm{mg} / \mathrm{kg}$ for E6010, $0.6 \mathrm{mg} / \mathrm{kg} / \mathrm{hr}$ for native t-PA and $1,000 \mathrm{IU} / \mathrm{kg} / \mathrm{min}$ for urokinase, since a previous study (9) showed that about $20 \mathrm{~min}$ was required to achieve complete reperfusion after administration of the drugs at these doses.

In the balloon occlusion-reperfusion group, the occlusive intracoronary balloon was abruptly deflated at 80 min after initiation of coronary artery occlusion, and the balloon catheter was withdrawn. Therefore, the reperfusion time from occlusion to complete reperfusion was the same (about $80 \mathrm{~min}$ ) in the four groups ( $\mathrm{n}=6$ each). Time to complete reperfusion in each group was determined by flowmetry and angiography.

The coronary flow before occlusion with the copper coil or the balloon was regarded as $100 \%$, and the percentage recovery of blood flow per minute was calculated from the time of drug administration or deflation of the balloon to the time of complete reperfusion. Therefore, the more gradually blood flow recovered, the smaller this value became.

PVC were counted after the 1-hr coronary occlusion during the $10-\mathrm{min}$ period before drug administration and from 10 to 20 , from 25 to 35 and from 55 to $65 \mathrm{~min}$ after complete reperfusion, and their frequencies were expressed as the mean value (beats $/ \mathrm{min}$ ). These values are referred to as Pre, $\mathrm{PVC}(15), \mathrm{PVC}(30)$ and $\mathrm{PVC}(60)$, respectively.

\section{Drugs}

E6010 and native t-PA were produced using recombinant techniques by Eisai Co., Ltd. (Tokyo). E6010 was constructed modifying only a single amino acid in the epidermal growth factor domain $\left(\mathrm{Cys}^{84} \rightarrow \mathrm{Ser}^{84}\right.$ ) by sitedirected mutagenesis. E6010 was cultured and purified on a mass scale by a genetic recombination technique in baby hamster kidney (BHK) cells. Its specific activity, estimated by the fibrin clot lysis method, was $15.0 \times 10^{4} \mathrm{IU} / \mathrm{mg}$ protein. Native t-PA was prepared by the same method and had a specific activity of $50.0 \times 10^{4} \mathrm{IU} / \mathrm{mg}$ protein. Urokinase was obtained from Green Cross Co., Ltd. (Tokyo), and its specific activity was $15.7 \times 10^{4} \mathrm{IU} / \mathrm{mg}$ protein.

\section{Statistical analyses}

The data are expressed as means \pm S.D. Statistical analyses were performed with the program Statview II on Macintosh computers. The groups were compared by one-way analysis of variance (ANOVA), and when there was a significant difference, Fisher's exact test was em-

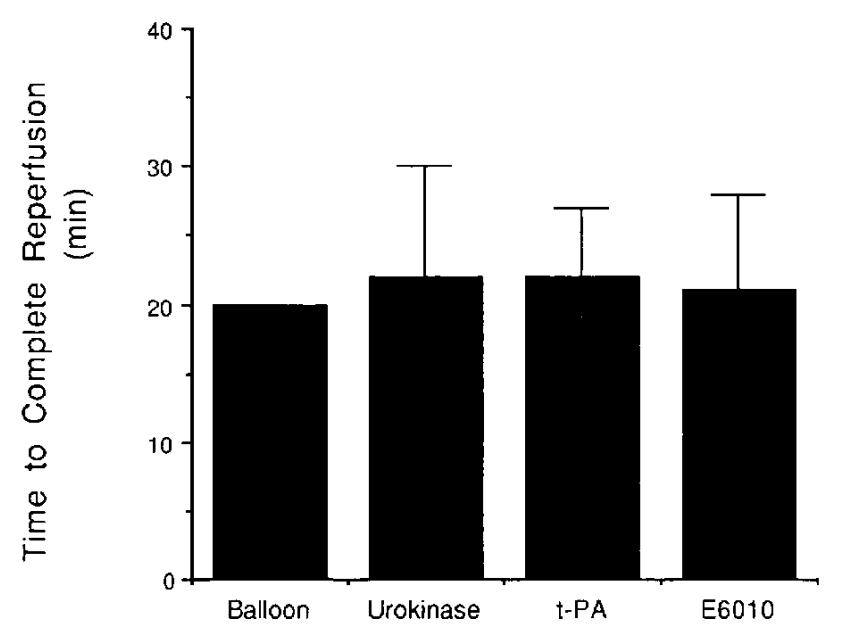

Fig. 2. Time to complete reperfusion in the balloon occlusionreperfusion, urokinase, native t-PA and E6010 groups. Urokinase, native t-PA or E6010 was administered after 1-hr coronary thrombosis induced by a copper coil. In the balloon occlusion-reperfusion group, the coronary artery was occluded with the balloon for $1 \mathrm{hr}$ and $20 \mathrm{~min}$ to approximately equalize the time to complete reperfusion with the other groups. Doses were $1,000 \mathrm{IU} / \mathrm{kg} / \mathrm{min}$ for urokinase, $0.6 \mathrm{mg} / \mathrm{kg} / \mathrm{hr}$ for native t-PA and $0.2 \mathrm{mg} / \mathrm{kg}$ for $\mathrm{E} 6010$. For urokinase and native t-PA, $10 \%$ of the dose was administered in bolus form, and the remaining $90 \%$ was infused continuously over a 60 -min period. E6010 was administered as a bolus. All drugs were administered intravenously. Values show the means \pm S.D. for 5-6 animals. 
ployed. Scheffe's multiple range test was used to make comparisons among the four groups (16). For determining significant differences in mortality rates, we used the chi-square test. A $P$ value less than 0.05 was considered significant.

\section{RESULTS}

\section{Comparison of time to complete reperfusion in the four groups}

As shown in Fig. 2, there were no significant differences among the groups in time to complete reperfusion, which occurred about $20 \mathrm{~min}$ after drug administration. Therefore, the time from occlusion to complete reperfusion was considered to have been similar in all groups.

\section{Comparison of reperfusion flow in the four groups}

Figure 3 shows the time course of the reperfusion blood flow in each animal after drug administration or balloon deflation. In the balloon occlusion-reperfusion group, one dog died immediately because of ventricular fibrillation after the complete reperfusion. Reperfusion occurred gradually after the administration of E6010 compared with the native t-PA, urokinase and balloon occlusionreperfusion groups. Figure 4 shows the reperfusion flow rate. The reperfusion flow was expressed as $\% / \mathrm{min}$, with lower values indicating more gradual reperfusion. This value was significantly lower in the E6010 group than in the urokinase, native t-PA and balloon occlusion-reperfusion groups $(\mathbf{P}<0.01)$.

\section{Comparison of premature ventricular complexes $(P V C)$ in the four groups}

Figure 5 shows the frequency of reperfusion arrhythmia per min. The majority of arrhythmias were ventricular in origin. The arrhythmia in the E6010 group was

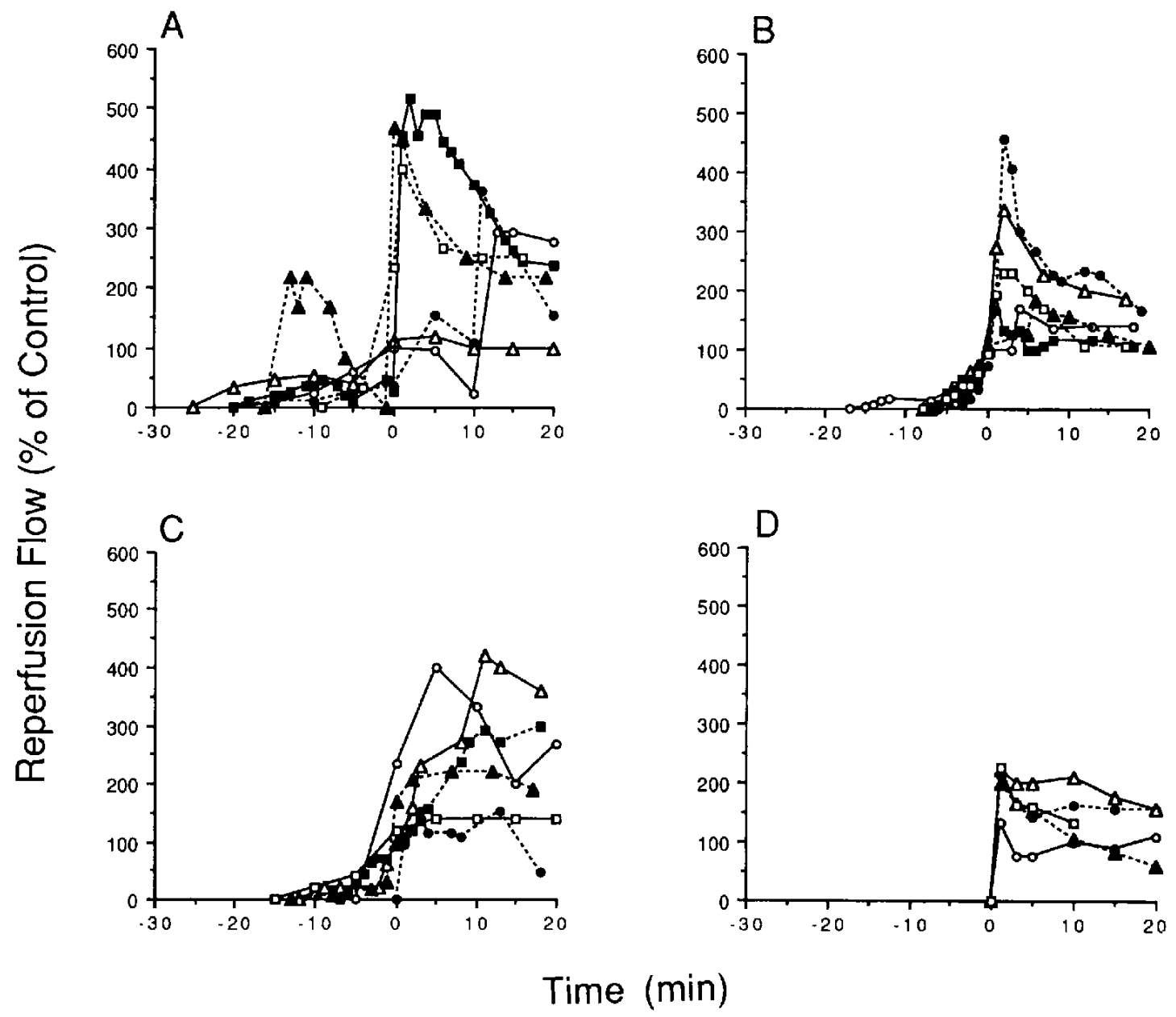

Fig. 3. Time course of the reperfusion blood flow in each animal after drug administration or balloon deflation. Data are expressed as a percent of the coronary flow before occlusion. Zero minute shows the time to complete reperfusion. In each panel, the same symbol shows the same animal, A: E6010, B: urokinase, C: native t-PA, D: balloon occlusion-reperfusion group. 


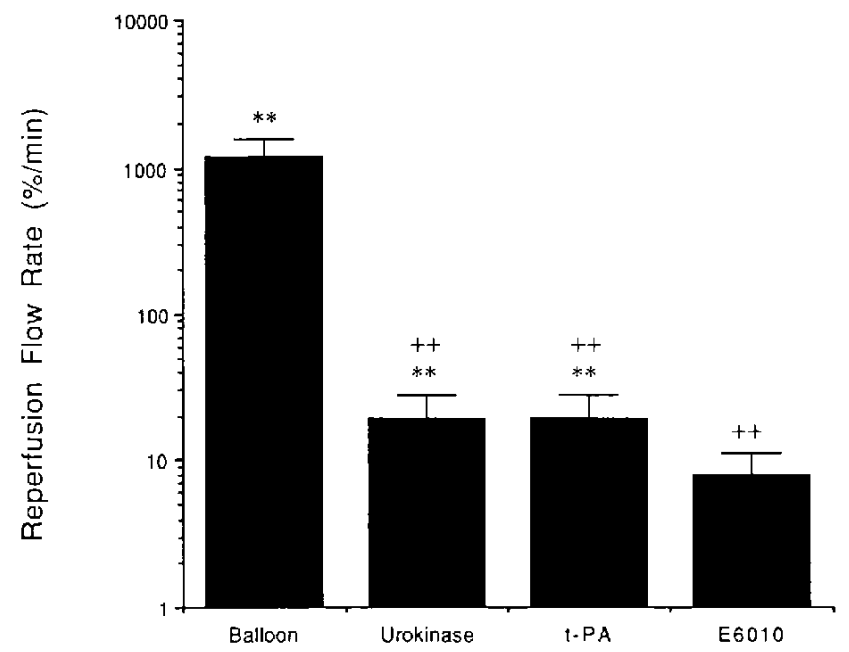

Fig. 4. Reperfusion flow rate in the balloon occlusion-reperfusion, urokinase, native t-PA and E6010 groups. The reperfusion flow rate is expressed as a percentage of recovery of blood flow per minute, calculated from the time after drug administration or deflation of the balloon to $100 \%$ recovery. See Fig. 1 for the doses and methods of administration. Values show the means \pm S.D. for 6 animals except the balloon occlusion-reperfusion group ( 5 animals). ${ }^{* *} \mathrm{P}<0.01$ vs. E6010, ${ }^{+} \mathrm{P}<0.01$ vs. balloon occlusion-reperfusion group.

significantly lower than both those in the balloon occlusion-reperfusion group at 30 and 60 min after reperfusion

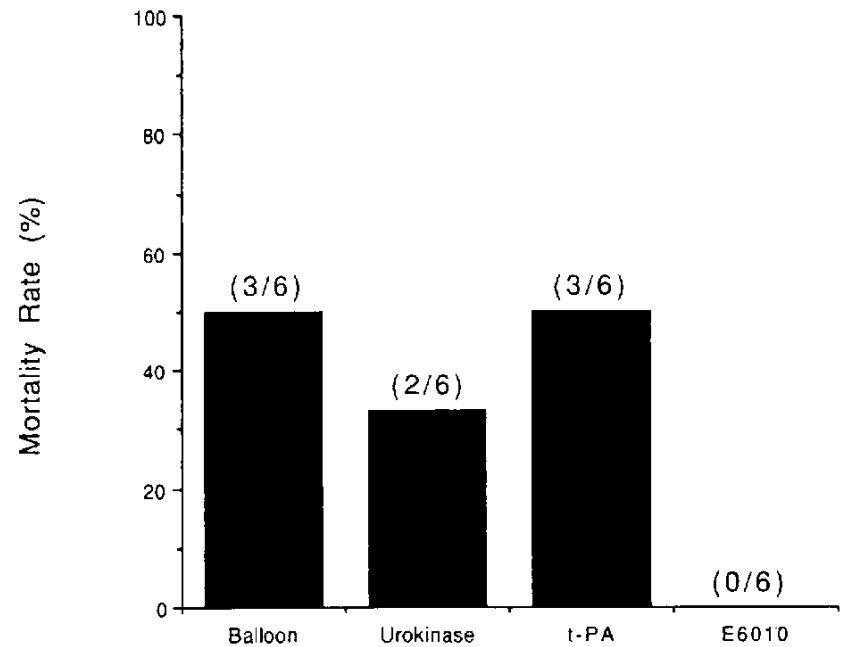

Fig. 6. Mortality rate in balloon occlusion-reperfusion, urokinase, native t-PA and E6010 groups. Mortality rate was expressed as the percentage of animals in each group of 6 that died due to ventricular fibrillation.

$(P<0.01)$ and that in the urokinase group 15 min after reperfusion $(\mathrm{P}<0.05)$. The frequency of $\mathrm{PVC}$ was increased compared with values before administration in the urokinase, native t-PA and balloon occlusion-reperfusion groups, whereas there was no significant increase in

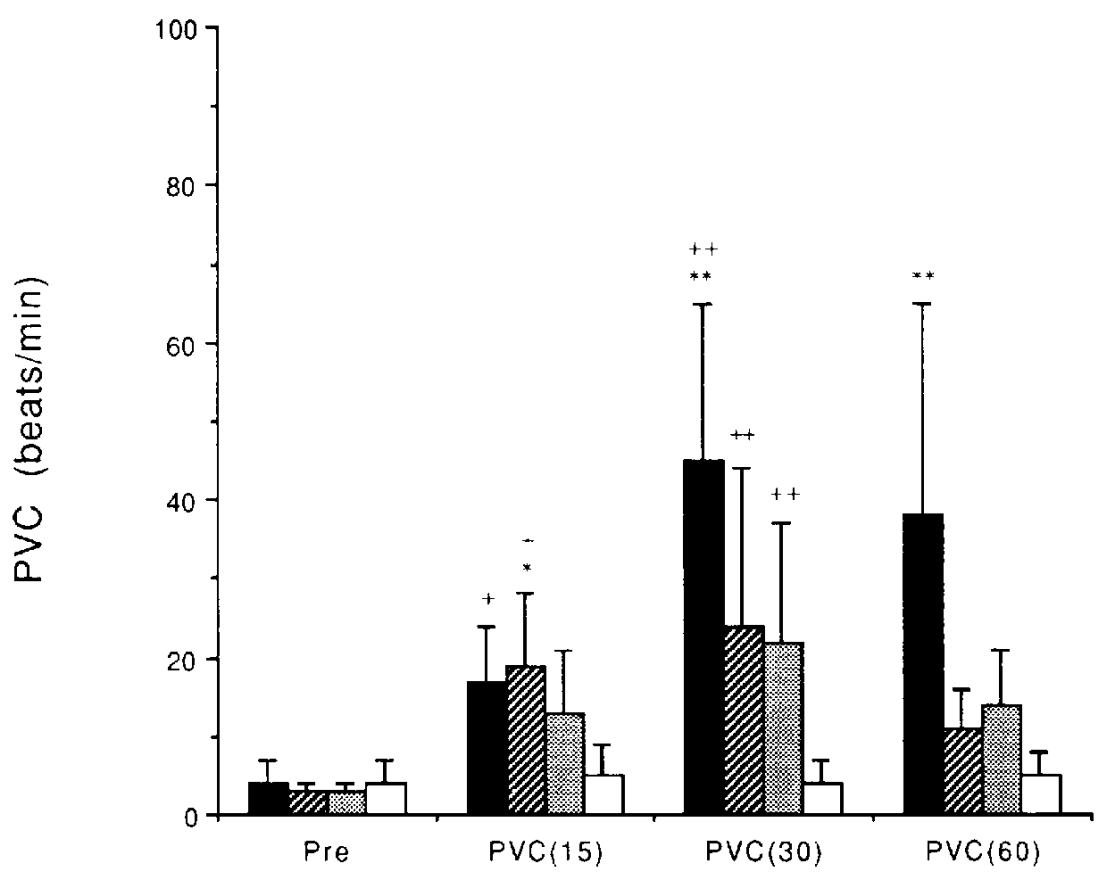

Fig. 5. Frequency of premature ventricular complexes (PVC) in balloon occlusion-reperfusion, urokinase, native t-PA and E6010 groups. Pre, PVC(15), PVC(30) and PVC(60) were expressed as the mean value (beats/min) during the 10-min period before drug administration, and from 10 to 20 , from 25 to 35 and from 55 to 65 min after reperfusion, respectively. Filled columns: balloon occlusion-reperfusion group, hatched columns: urokinase, dotted columns: native t-PA, open columns: E6010. Values show the means + S.D. for $3-6$ animals. ${ }^{*} \mathrm{P}<0.05,{ }^{* * *} \mathrm{P}<0.01$ vs. E6010, ${ }^{-} \mathrm{P}<0.05,{ }^{++} \mathrm{P}<0.01$ vs. Pre. 
the E6010 group.

\section{Comparison of mortality rate in the four groups}

Figure 6 shows the mortality rate, which was $0.0 \%$ $(0 / 6)$ in the E6010 group, $33.3 \%(2 / 6)$ in the urokinase group and $50.0 \%(3 / 6)$ in the t-PA and balloon occlusionreperfusion groups. Although the mortality rate was not significantly different among the four groups, the rate in the E6010 group was lower than those in the urokinase, native t-PA and balloon occlusion-reperfusion groups.

\section{DISCUSSION}

In experimental canine studies, Reimer et al. (17) found that although significant myocardial salvage was achieved when flow was restored after $15 \mathrm{~min}$ of acute ischemia, regional function recovered neither rapidly nor fully. Furthermore, there have been many previous experimental reports of serious arrhythmias induced by the rapid release of coronary occlusion (18-20). In clinical studies, Goldberg et al. (21) reported that reperfusion arrhythmias occurred in $82 \%$ of patients during restoration of anterograde coronary flow, and Mathey et al. (22) reported that 5 of 41 patients showed ventricular fibrillation during thrombolytic reperfusion. In reperfusion arrhythmias, there may be increased heterogeneity of electrical activity in necrotic versus viable cells, leading to the instability of the cell membrane balance (20); the etiology of reperfusion arrhythmias appears to be different from that of arrhythmias produced during coronary occlusion (18). Several investigators $(21,23-25)$ have reported that accelerated idioventricular rhythm exhibited a peak incidence during the first $3 \mathrm{hr}$ after reperfusion.

It has been suggested that a more gradual reperfusion might be beneficial $(25-27)$. Rapid washout of extracellular electrolytes, etc. during reperfusion may also account for the electrophysiological changes related to arrhythmogenesis (19). Moschos et al. (27) observed that serious arrhythmias were less frequent when the intracoronary lysis was achieved gradually, and Yamazaki et al. (25) reported that the incidence of idioventricular complexes in a staged reperfusion group was much lower than that in a sudden reperfusion group. Indeed, although in the present study heart rate, mean blood pressure, left ventricular pressure (LVP), $\mathbf{L V d p} / \mathrm{dt}$ and left ventricular end-diastolic pressure were recorded throughout the experiment, they could not analyzed during some periods due to reperfusion arrhythmias, especially in the native $t-$ PA, urokinase and balloon occusion-reperfusion groups. However, Ibuki et al. (28) reported that restricted reflow delayed the time to onset of reperfusion-induced ventricular fibrillation, but did not reduce the incidence of reperfusion-induced ventricular tachycardia or fibrillation in per- fused hearts. These studies have largely been limited to experimental models of mechanical occulusion and reperfusion achieved by transiently clamping the coronary artery. These differences are considered to be due to differences in the manner whereby thrombolysis is induced; i.e., arrhythmias are prevented by gradually lysing the thrombi and slowly restoring the blood flow beginning early after administration.

In the present study, we evaluated the manner in which thrombolysis was induced by various thrombolytic agents by measuring the coronary blood flow during thrombolysis. The blood flow increased gradually beginning immediately after administration of E6010, whereas it increased significantly more sharply after administration of native t-PA or urokinase. The frequency of PVC was significantly lower in the E6010 group than in the native t-PA, urokinase or balloon occlusion-reperfusion groups, and it was not increased compared with the preadministration level. Mortality rate was also lower in the E6010 group than in the t-PA, urokinase and balloon occlusion-reperfusion groups. The doses of the thrombolytic agents were adjusted to equalize the time to the recovery of the coronary blood flow to the preocclusion level. Therefore, since complete reperfusion occurred at approximately the same intervals after administration, we considered that differences in the frequency of PVC and mortality rate were not due to differences in the time from occlusion to complete reperfusion. The plasma half-life of E6010 is about 1.4 times longer than that of t-PA in dogs, and a high plasma concentration can be maintained beginning immediately after intravenous bolus injection (9). On the other hand, the plasma half-life of native t-PA is short, so that it must be administered continuously if administered in travenously, and a considerable time is needed until its plasma concentration is sufficiently increased. Thus, the thrombolytic effect of E6010 was produced earlier after administration compared with that of native t-PA.

Hospital mortality has clearly decreased since the introduction of thrombolytic therapy, and long-term prognosis including the recovery of cardiac function are expected to be further improved by the development of new drugs similar to native t-PA. In the present study, we showed that E6010 produced a sufficient thrombolytic effect when administered as an intravenous bolus and that it caused reperfusion arrhythmias less frequently than the other thrombolytic agents or mechanical reperfusion. Therefore, we consider that E6010 provides effective and safe treatment for acute myocardial infarction from an early period after onset and that the drug has promising potential as a new treatment for this disease.

\section{Acknowledgments}

We thank Mr. A. Hashimoto and his colleagues in Eisai Co., Ltd., 
for providing the recombinant proteins and Mr. Daniel Mrozek for reading the draft and providing suggestions on language and style.

\section{REFERENCES}

I Manning AS and Hearse DJ: Reperfusion-induced arrhythmias: mechanisms and prevention. J Mol Cell Cardiol 16, $497-518$ (1984)

2 ISIS-2 Collaborative Group: Randomised trial of intravenous streptokinase, oral aspirin, both, or neither among 17,187 cases of suspected acute myocardial infarction: ISIS-2. Lancet 2, $349-360$ (1980)

3 Gruppo Italiano per lo Studio della Streptochinasi nell'Infarto Miocardico (GISSI): Effectiveness of intravenous thrombolytic treatment in acute myocardial infarction. Lancet 1, 397-402 (1986)

4 Global Utilization of Streptokinase and Tissue Plasminogen Activator for Occluded Coronary Arteries (GUSTO) Trial Study: The effects of tissue plasminogen activator, streptokinase, or both on coronary-artery patency, ventricular function, and survival after acute myocardial infarction. N Engl J Med 329, $1615-1622$ (1993)

5 Linderer T, Schroder R, Arntz R, Heineking M, Wunderlich W, Kohl K, Forycki F, Henzgen R and Wagner J: Prehospital thrombolysis: beneficial effects of very early treatment on infarct size and left ventricular function. J Am Coll Cardiol 22, $1304-1310$ (1993)

6 Suzuki S, Saito M, Suzuki N, Yui Y and Kawai C: A novel modified t-PA (Mf-tPA, E6010). Circulation 78, Supp II-651 (1988)

7 Suzuki S, Saito M, Suzuki N, Nagaoka N, Mizuo H, Yuzuriha T, Yoshitake S, Yui Y and Kawai C: Coronary thrombolysis with a novel modified t-PA (Mf-tPA, E6010) in dogs. Jpn Circ J 53, 916-917 (1989)

8 Saito M, Suzuki S, Suzuki N, Nagaoka N, Yoshitake S, Mizuo H, Yuzuriha T, Yui Y and Kawai C: Comparison of thrombolytic efficacy between native (rt-PA) and modified human tissuetype plasminogen activator (Mf-tPA, E6010) on the duration of coronary thrombus. Jpn Circ J 53, 917 (1989)

9 Suzuki S, Saito M, Suzuki N, Kato H, Nagaoka N, Yoshitake S, Mizuo H, Yuzuriha T, Yui Y and Kawai C: Thrombolytic properties of a novel modified human tissue-type plasminogen activator (E6010): A bolus injection of E6010 has equivalent potency of lysing young and aged canine coronary thrombi. J Cardiovasc Pharmacol 17, 738-746 (1991)

10 Suzuki S, Saito M, Suzuki N, Kato H, Nagaoka N, Yoshitake S, Yui Y and Kawai C: Intracoronary infusion of E6010 has more potent thrombolytic activity than tissue plasminogen activator (t-PA) in dogs: A higher plasma level of E6010 than t-PA causes potent thrombolytic activity. J Cardiovasc Pharmacol 22, 834-840 (1993)

11 Kawai C, Hosoda S, Motomiya T, Kimata S, Yui Y, Kodama K, Minamino R, Sato $\mathrm{H}$ and Nobuyoshi M: Multicenter trial of a novel modified t-PA, E6010, by i.v. bolus injection in patients with acute myocardial infarction [Abstract 1630]. Circulation 86, I-409 (1992)

12 Janse MJ: The premature beat. Cardiovasc Res 26, 89-100 (1992)
13 Saito M, Suzuki S, Suzuki N, Yui Y and Kawai C: Reduction of reperfusion arrhythmia and mortality rate in coronary thrombolysis by the second generation t-PA (E6010). I Mol Cell Cardiol 22, Supp III, S74 (1990)

14 Saito M, Suzuki S, Suzuki N, Yui Y and Kawai C: The second generation t-PA (E6010) reduces reperfusion arrhythmia and mortality rate induced after coronary thrombolysis. Eur Heart J 11, Supp 315 (1990)

15 Kordenat RK, Kezdi P and Stanley EL: A new catheter technique for producing experimental coronary thrombosis and selective coronary visualization. Am Heart J 83, 360-364 (1972)

16 Wallenstein S, Zucker CL and Fleiss JL: Some statistical methods useful in circulation research. Circ Res 47, $1-9$ (1980)

17 Reimer KA, Jennings RB and Tatum AH: Pathobiology of acute myocardial ischemia: metabolic function and ultrastructural studies. Am J Cardiol 52, 72A-81A (1983)

18 Battle WE, Naimi S, Avitall B, Brilla AH, Banas IS Jr, Bete $\mathrm{JM}$ and Levine HJ: Distinctive time course of ventricular vulnerability to fibrillation during and after release of coronary ligation. Am J Cardiol 34, 42-47 (1974)

19 Axelrod PJ, Verrier RL and Lown B: Vulnerability to ventricular fibrilation during acute coronary occlusion and release. Am J Cardiol 36, 776-782 (1975)

20 Murdock DK, Loeb JM, Euler DE and Randall WC: Electrophysiology of coronary reperfusion. A mechanism for reperfusion arrhythmias. Circulation 61, 175-182 (1980)

21 Goldberg S, Greenspan AJ, Urban PL, Muza B, Berger B, Walinsky $P$ and Maroko PR: Reperfusion arrhythmia: a marker of restoration of antegrade flow during intracoronary thrombolysis for acute myocardial infarction. Am Heart J 105, 26-32 (1983)

22 Mathey DG, Kuck KH, Tilsner V, Krebber HJ and Bleifeld W: Nonsurgical coronary artery recanalization in acute transmural myocardial infarction. Circulation 63, 489-497 (1981)

23 Thrombolysis and Angioplasty in Myocardial Infarction (TAMI) Study Group: Failure of simple clinical measurements to predict perfusion status after intravenous thrombolysis. Ann Intern Med 108, 658-662 (1988)

24 Nejima J, Knight DR, Fallon JT, Umemura N, Manders WT, Canfield DR, Cohen MV and Vatner SF: Superoxide dismutase reduces reperfusion arrhythmias but fails to salvage regional function or myocardium at risk in conscious dogs. Circulation 79, $143-153$ (1989)

25 Yamazaki S, Fujibayashi Y, Rajagopalan RE, Meerbaum S and Corday E: Effects of staged versus sudden reperfusin after acute coronary occlusion in the dog. J Am Coll Cardiol 7, 564-572 (1986)

26 Rentrop P, Blanke H, Karsch KR, Kaiser H, Kostering $H$ and Leitz K: Selective intracoronary thrombolysis in acute myocardial infarction and unstable angina pectoris. Circulation 63, 307-317 (1981)

27 Moschos CB, Burke WM, Lehan PH, Oldewurtel HA and Regan TJ: Thrombolytic agents and lysis of coronary artery thrombosis. Cardiovasc Res 4, $228-234$ (1970)

28 Ibuki C, Hearse DJ and Avkiran M: Rate of reflow and reperfusion induced arrhythmias: studies with dual coronary perfusion. Cardiovasc Res 26, 316-323 (1992) 